\title{
Determination of Natural Radioactivity Concentrations in Surface Soils in the Yeşilırmak River in Amasya, Turkey
}

\author{
B. ÇETIN* \\ Amasya University, Physics Department, Amasya, Turkey
}

\begin{abstract}
In this study, natural radioactivity concentration in the surface soils along the Yesilırmak river in Amasya have been investigated. The activity concentrations of radionuclides of the ${ }^{226} \mathrm{Ra}$ and ${ }^{232} \mathrm{Th}$ decay chains and of the ${ }^{40} \mathrm{~K}$ were determined by means of gamma-ray spectrometry measurements made using a $3 \times 3^{\prime \prime} \mathrm{NaI}(\mathrm{Tl})$ detector system. Concerning radiological risk, the absorbed gamma dose in air from those soils and the outdoor annual effective dose equivalent were calculated.
\end{abstract}

DOI: 10.12693/APhysPolA.130.320

PACS/topics: 29.90.+r, 29.30.-h

\section{Introduction}

Radioactive nuclei were created at the beginning of the universe and having long half-life, exist in the present Earth's crust. The human population is always exposed to ionizing radiation due to background radiation. The radiation caused by radionuclides located in the depths of the Earth contributes to daily natural background radiation. These radionuclides generally occur in the ground-source materials (stone, soil, rocks, etc.) in different quantities. The most important part of that radiation is due to presence of the uranium, thorium and potassium in the material.

As natural radiation is the largest contributor to the external radiation dose of the population, it is important to assess the gamma radiation dose from natural sources [1]. Thus it is important to measure the natural radioactivity and there have been several works performed to measure ${ }^{226} \mathrm{Ra},{ }^{232} \mathrm{Th}$ and ${ }^{40} \mathrm{~K}$ activity concentration in different materials [2-6].

For this purpose in this study, the concentrations of natural radioactivity levels of the soil in Amasya region have been determined. Gamma-ray spectra were recorded using the MAESTRO-32 gamma spectroscopy software on a $\gamma$-ray spectrometer system with a $\mathrm{NaI}(\mathrm{Tl})$ detector, coupled to a digital full featured $16 \mathrm{~K}$ multichannel spectrum analyzer (DSPEC LF), with advanced digital signal processing techniques. The specific activities for ${ }^{226} \mathrm{Ra}(1760 \mathrm{keV}),{ }^{232} \mathrm{Th}(2610 \mathrm{keV})$ and ${ }^{40} \mathrm{~K}$ $(1460 \mathrm{keV})$, in the Amasya soil samples, were found to be in the range of $22.48-41.88 \mathrm{~Bq} / \mathrm{kg}, 21.18-38.14 \mathrm{~Bq} / \mathrm{kg}$ and $293.44-443.44 \mathrm{~Bq} / \mathrm{kg}$, respectively. Radium equivalent activities $R a_{\mathrm{eq}}$ and external hazard index $H_{\mathrm{ex}}$ associated with the natural radionuclides were calculated to assess the radiation hazard of the natural radioactivity in Amasya soil samples.

*e-mail: betulcetin3205@gmail.com

\section{Materials and methods}

\subsection{Sample collection and preparation}

Soil samples were collected at five different spots to determine the natural radioactivities. Samples were crushed and dried at $100{ }^{\circ} \mathrm{C}$ in an oven for about 20 hours. The samples then were sieved and hermetically sealed in cylindrical plastic boxes which were closed tightly to limit, as far as possible, the escape of radon. The samples were then stored for more than 20 days before measurement, so as to ensure that ${ }^{238} \mathrm{U}$ atoms attain radioactive equilibrium with their derivatives.

\subsection{Activity measurement}

The natural radioactivity of ${ }^{226} \mathrm{Ra},{ }^{232} \mathrm{Th}$ and ${ }^{40} \mathrm{~K}$ in the Amasya soil samples was determined using the gamma spectrometer system [7-9]. The activity concentrations for the natural radionuclides in the measured soil samples were computed using the following relation $[3,4]$

$$
A=\frac{C}{\varepsilon \gamma t m},
$$

where $A$ is the activity of the isotope in $\mathrm{Bq} / \mathrm{kg}, C$ is the net count rate under the most prominent photo peaks, calculated by subtracting from the raw count rate the background spectrum, obtained during the same counting time, $\varepsilon$ is the detector efficiency with respect to the specific gamma rays, $\gamma$ is the absolute transition probability of gamma decay, $t$ is counting time (s) and $m$ is the mass of the sample $(\mathrm{kg})$.

\section{Results and discussion}

The activity concentrations of ${ }^{226} \mathrm{Ra},{ }^{232} \mathrm{Th}$ and ${ }^{40} \mathrm{~K}$ have been measured in five different Amasya soil samples. The results are shown in Fig. 1, where the activity variation for these soil samples can be seen. The worldwide concentrations of the radionuclides are $40 \mathrm{~Bq} / \mathrm{kg}$ for uranium and thorium series and $580 \mathrm{~Bq} / \mathrm{kg}$ for ${ }^{40} \mathrm{~K}$ [1]. It can be seen that only in one region ${ }^{226} \mathrm{Ra}$ activity value seem to exceed the world's average value. 


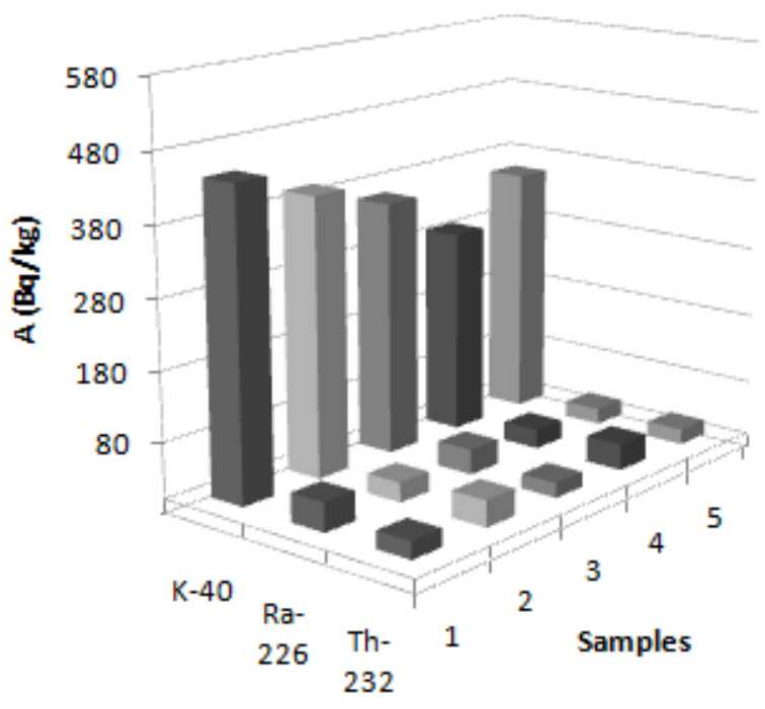

Fig. 1. Ra, Th and K activity in Amasya soil samples.

As the distribution of ${ }^{226} \mathrm{Ra},{ }^{232} \mathrm{Th}$ and ${ }^{40} \mathrm{~K}$ in soil samples is not uniform, the uniformity with respect to exposure to radiation has been defined in terms of radium equivalent activity $R a_{\text {eq }}$ in $\mathrm{Bq} / \mathrm{kg}$. In order to compare the specific activity of materials containing different amounts of ${ }^{226} \mathrm{Ra},{ }^{232} \mathrm{Th}$ and ${ }^{40} \mathrm{~K}, R a_{\text {eq }}$ is calculated using the following relation $[10,11]$ :

$$
R a_{\mathrm{eq}}=C_{\mathrm{Ra}}+1.43 C_{\mathrm{Th}}+0.077 C_{\mathrm{K}},
$$

where $C_{\mathrm{Ra}}, C_{\mathrm{Th}}$ and $C_{\mathrm{K}}$ are the activity concentrations of ${ }^{226} \mathrm{Ra},{ }^{232} \mathrm{Th}$ and ${ }^{40} \mathrm{~K}$, respectively, in $\mathrm{Bq} / \mathrm{kg}$. The results are displayed in Fig. 2. The $R a_{\mathrm{eq}}$ values are lower than the recommended maximum limit value of $370 \mathrm{~Bq} / \mathrm{kg}[6]$.

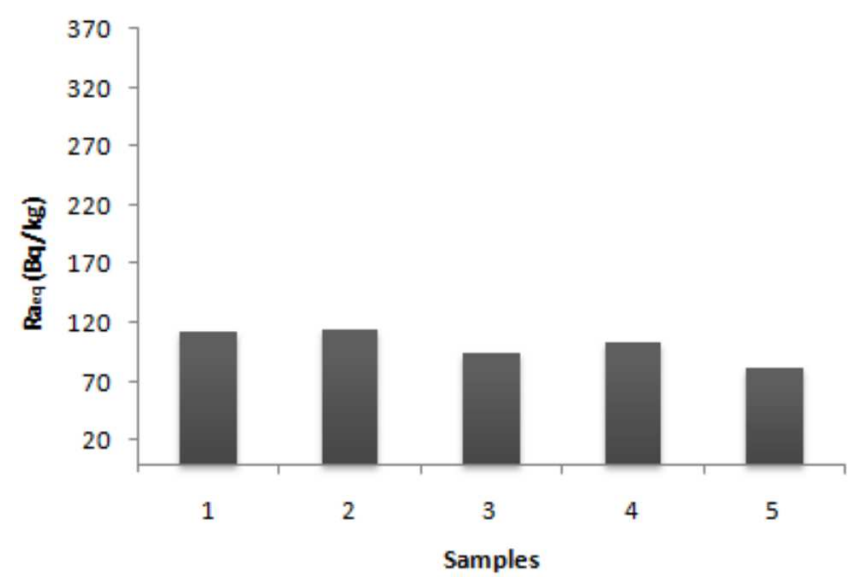

Fig. 2. Radium equivalent activity for soil samples.

The external hazard index $H_{\mathrm{ex}}$ was calculated using equation [10]:

$$
H_{\mathrm{ex}}=\frac{C_{\mathrm{Ra}}}{370}+\frac{C_{\mathrm{Th}}}{259}+\frac{C_{\mathrm{K}}}{4810} \leq 1,
$$

where $C_{\mathrm{Ra}}, C_{\mathrm{Th}}$ and $C_{\mathrm{K}}$ are the activity concentrations of ${ }^{226} \mathrm{Ra},{ }^{232} \mathrm{Th}$ and ${ }^{40} \mathrm{~K}$, respectively, in $\mathrm{Bq} / \mathrm{kg}$. Results are shown in Fig. 3. It is assumed that $370 \mathrm{~Bq} / \mathrm{kg}$ of ${ }^{226} \mathrm{Ra}$, $259 \mathrm{~Bq} / \mathrm{kg}$ of ${ }^{232} \mathrm{Th}$ and $4810 \mathrm{~Bq} / \mathrm{kg}$ of ${ }^{40} \mathrm{~K}$ produce the same gamma ray dose $[11,12]$. The value of $H_{\mathrm{ex}}$ must be less than unity. The results range from 0.22 to 0.31 .

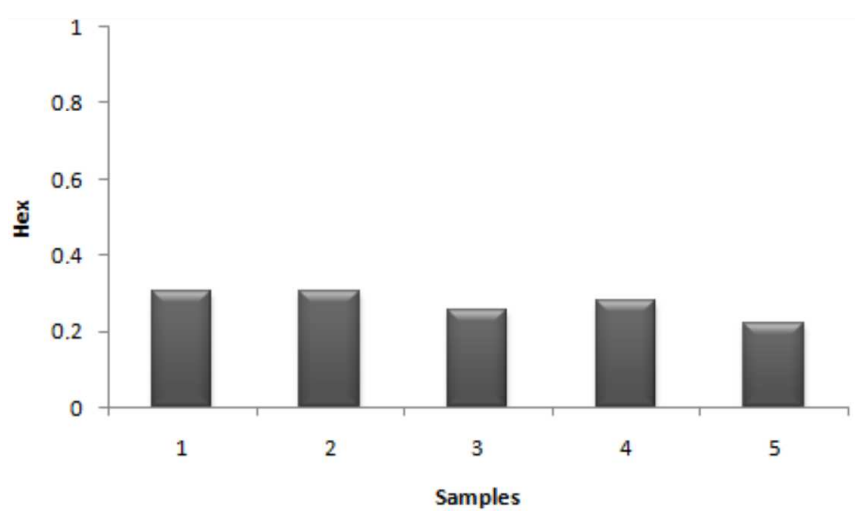

Fig. 3. Hazard index for all measured samples and comparison with the limit value.

\section{References}

[1] UNSCEAR, Sources, Effects and Risks of Ionizing Radiation. Report to the General Assembly with Annex A: Exposures from Natural Sources of Radiation, United Nations, New York 1993.

[2] B.U. Chang, S.M. Koh, Y.J. Kim, J.S. Seo, Y.Y. Yoon, J.W. Row, D.M. Lee, J. Environ. Radioactiv. 99, 455 (2008).

[3] İ. Akkurt, B. Mavi, H. Akyıldırım, K. Günoğlu, Int. J. Phys. Sci. 4, 403 (2009).

[4] B. Mavi, İ. Akkurt, Radiat. Phys. Chem. 79, 933 (2010).

[5] S. Turhan, U.N. Baykan, K. Sen, J. Radiol. Prot. 28, 83 (2008).

[6] N. Ayten Uyanık, O. Uyanık, İ. Akkurt, J. Appl. Geophys. 98, 191 (2013).

[7] I. Akkurt, C. Basyigit, S. Kilincarslan, B. Mavi, A. Akkurt, Cement Concrete Compos. 28, 153 (2006).

[8] I. Akkurt, H. Akyıldırım, B. Mavi, S. Kilincarslan, C. Basyigit, Ann. Nucl. Energy 37, 910 (2010).

[9] I. Akkurt, Ann. Nucl. Energy 36, 1702 (2009).

[10] J. Beretka, P.J. Mathew, Health Phys. 48, 8795 (1985).

[11] E. Stranden, Health Phys. 8, 167 (1976)

[12] E.M. Krisiuk, S.I. Tarasov, V.P. Shamov, N.I. Shalak, E.P. Lysachenko, L.G. Gomelsky, A Study of Radioactivity in Building Material, Leningrad Research Institute for Radiation Hygiene, Leningrad 1971. 